\title{
OS ÁCIDOS GRAXOS DE CADEIA CURTA NA CICATRIZAÇÃO DE ANASTOMOSES COLÔNICAS: ESTUDO EXPERIMENTAL EM RATOS
}

\author{
THE SHORT CHAIN FATTY ACIDS ON COLONIC ANASTOMOSIS HEALING: \\ EXPERIMENTALSTUDY ON RATS
}

\author{
Fernando Hintz Greca, TCBC-PR ${ }^{1}$ \\ Maria de Lourdes Pessole Biondo-Simões, TCBC-PR ${ }^{2}$ \\ Vanessa Dello Monaco Martins ${ }^{3}$ \\ Fábio Henrique de Araújo ${ }^{3}$ \\ Jerônimo Buzetti Milano ${ }^{3}$
}

\begin{abstract}
RESUMO:Objetivo: Avaliar a ação dos ácidos graxos de cadeia curta (AGCC) na cicatrização de anastomoses colônicas em ratos. Método: Utilizaram-se 50 ratos divididos em 4 grupos. Dois desses grupos, vinte e seis animais, foram submetidos à operação de Hartmann; metade destes (grupo HF) recebeu infusões retais diárias, no pósoperatório, de solução fisiológica a $0,9 \%$; a outra metade (grupo HA) recebeu solução de butirato de sódio à 80mmol/l (AGCC) (HA). Os dois grupos restantes, vinte e quatro animais foram submetidos à anastomose colônica término-terminal a $4 \mathrm{~cm}$ da borda anal. Destes, 12 animais (grupo AF) receberam infusões retais de soro fisiológico a $0,9 \%$ e 12 animais (grupo AA) receberam a solução com AGCC. Os animais foram avaliados no $7^{\circ}$ e $14^{\circ}$ dia do pósoperatório. Foi realizada análise histológica da densitometria do colágeno pela coloração do sirius red, utilizandose a microscopia de polarização com método computadorizado. Resultados: Comparando-se os grupos submetidos à cirurgia de Hartmann, portanto na ausência do trânsito intestinal, observou-se concentração significativamente maior de colágeno I e total no grupo que recebeu AGCC $(\mathrm{p}=0,001)$. Comparando-se os grupos submetidos à anastomose término-terminal, com interferência do trânsito intestinal, não se encontrou diferença significante da concentração de colágeno I e total ( $\mathrm{p}=0,056$ e p=0,397, respectivamente). A ação isolada do trânsito intestinal promoveu também aumento da produção de colágeno, quando comparado ao grupo sem atuação do trânsito intestinal. Conclusão: A administração via retal de AGCC, na ausência do trânsito intestinal mostrou-se de grande valia, promovendo aumento da síntese do colágeno. Independentemente da interferência do trânsito intestinal, o principal efeito do AGCC esteve relacionado com o aumento da maturação do colágeno.
\end{abstract}

Descritores: Ácidos graxos voláteis; Cicatrização de feridas; Cólon; Colágeno; Anastomose cirúgica.

\section{INTRODUÇÃO}

Além da absorção de água, com eficiência de 99\%, o cólon participa na absorção de sódio, cloro, amônia, vitaminas e ácidos graxos de cadeia curta. Estas substâncias estão relacionadas com a manutenção do pH intestinal, com trofismo da mucosa colônica e proteção da microbiota normal, evitando o crescimento de bactérias patogênicas.

1. Professor Adjunto de Técnica Cirúrgica e Cirurgia Experimental - UFPR; Professor Titular de Técnica Operatória e Cirurgia Experimental da PUCPR; Doutor em Cirurgia Experimental pela UNIFESP-EPM.

2. Coordenadora da Disciplina de Técnica Cirúrgica e Cirurgia Experimental - UFPR; Professora Titular de Técnica Operatória e Cirurgia Experimental da PUCPR; Doutora em Cirurgia Experimental pela UNIFESP-EPM.

3. Alunos do $6^{\circ}$ ano do Curso de Medicina e Monitores da Disciplina de Técnica Cirúrgica e Cirurgia Experimental - UFPR.

Recebido em 04/02/2002

Aceito para publicação em 13/08/2002

Projeto de pesquisa desenvolvido na Disciplina de Técnica Cirúrgica e Cirurgia Experimental do Departamento de Cirurgia do Hospital de Clínicas da Universidade Federal do Paraná (UFPR) e da Pontifícia Universidade Católica do Paraná (PUCPR). 
Os ácidos graxos de cadeia curta (AGCC) são substâncias produzidas a partir da fermentação anaeróbica das fibras ingeridas na dieta pelas bactérias presentes na luz do órgão. Trabalhos experimentais em ratos demonstraram que a desfuncionalização do cólon por um período de quatro semanas pode ocasionar a atrofia não só da mucosa como de toda a parede da víscera' ${ }^{1,2}$. Isto pode ser observado freqüentemente na prática cirúrgica, quando por qualquer razão o conteúdo colonico é desviado, privando assim, a mucosa do contato com as fezes. Essa torna-se atrófica, sangrando aos mínimos traumatismos.

Um dos procedimentos mais comumente usados para o desvio do trânsito fecal, em situações de emergência, é a operação de Hartmann, que consiste de uma colostomia proximal e fechamento do coto distal do reto. O momento, entretanto, para reconstituir o trânsito digestivo é ainda muito controverso, pois está associado a uma significativo aumento da morbidade e da mortalidade pós-operatória, decorrentes de diversas complicações inerentes a este procedimento ${ }^{3}$. Keck et al ${ }^{4}$ refere um maior número de dificuldades trans-operatórias, quando a reconstituição do trânsito fecal se deu num período menor que 15 semanas em relação à primeira operação, devido à grande densidade de aderências e, com isto, maiores riscos de lesões inadvertidas do intestino delgado. Pearce $e t a l{ }^{5}$ no entanto, relataram maiores índices de deiscência da anastomose, quando o intervalo entre a primeira e a segunda operação era maior que seis meses, período este suficiente para ocasionar a atrofia da parede do cólon desfuncionalizado.

Como meio de reverter ou evitar o processo de atrofia da mucosa colônica, tem sido preconizado a infusão de ácidos graxos de cadeia curta. O butirato, um dos principais AGCC, apresenta-se como fonte de energia primária para os colonócitos ${ }^{6}$ e estimula a proliferação celular do epitélio do cólon ${ }^{7}$. Rolandelli et $a l^{8}$ demostraram que a infusão intraluminar de AGCC facilitava o processo cicatricial das anastomoses colônicas em ratos. Mecanismos possíveis que possam mediar este efeito incluem o aumento da proliferação celular da mucosa colônica, acelerando a reepitelização e o aumento do fluxo sangüíneo com conseqüente aumento da oferta de oxigênio e aceleração da maturação do colágeno.

Atualmente tem-se utilizado a infusão de AGCC até mesmo em humanos na tentativa de se evitar a atrofia da mucosa, após a realização da cirurgia de Hartmann. Observou-se que naqueles pacien- tes que receberam o AGCC ocorreu aumento da atividade proliferativa da mucosa retal, quando comparados àqueles que não receberam? ${ }^{9}$.

O presente estudo tem como objetivo avaliar a interferência dos ácidos graxos de cadeia curta no processo de fibroplasia e cicatrização colônica.

\section{MÉTODO}

O desenvolvimento deste estudo obedeceu à Lei Federal 6.638 e às orientações do Colégio Brasileiro de Experimentação Animal.

Foram utilizados 50 ratos (Rattus norvegicus albinus, Rodentia mammalia) da linhagem WistarTECPAR, com peso entre 180 e 200 gramas, provenientes do Instituto de Tecnologia do Paraná, os quais permaneceram confinados em caixas apropriadas para a espécie, com livre acesso à água e à ração padronizada.

Dos 50 animais, 26 foram submetidos à operação de Hartmann; metade destes receberam infusões retais diárias, no pós-operatório, de solução fisiológica a $0,9 \%$ (grupo HF) e os demais (grupo HA) receberam solução de butirato de sódio à $80 \mathrm{mmol} / 1$ (AGCC) . Vinte e quatro animais foram submetidos à anastomose colônica término-terminal a $4 \mathrm{~cm}$ da borda anal. Destes, 12 animais receberam infusões retais de solução fisiológica a 0,9\% (grupo AF) e 12 animais receberam a solução com AGCC (grupo AA). Os animais foram avaliados no $7^{\circ}$ e $14^{\circ}$ dia do pósoperatório.

Todos os ratos foram submetidos a jejum préoperatório de 12 horas. Realizou-se limpeza intestinal imediatamente antes do procedimento cirúrgico, estimulando-se o reflexo da defecação. Tanto a indução quanto a manutenção anestésica foram realizadas com éter dietílico por via inalatória. Em condições de antisepsia, realizou-se a laparotomia mediana de aproximadamente $4 \mathrm{~cm}$ e secção do cólon a $2,5 \mathrm{~cm}$ da reflexão peritoneal.

A operação de Hartmann foi então realizada com o fechamento do coto intestinal distal e exteriorização do coto proximal em forma de uma colostomia terminal. O coto distal foi fechado com sutura contínua, e o proximal fixado à pele com seis pontos simples. A colostomia foi localizada a $1,5 \mathrm{~cm}$ acima do púbis, e 1,0 cm à direita em relação à linha abdominal mediana. Utilizou-se fio monofilamentar de náilon 6.0 em ambas as sínteses. Nos animais submetidos à anastomose colônica, utilizou-se a mesma 
via de acesso; a anastomose foi realizada a $2,5 \mathrm{~cm}$ da reflexão peritoneal, com oito pontos interrompidos, do mesmo fio.

Os animais do grupo controle receberam infusões retais de solução salina isotônica a $0,9 \%$ através de seringa descartável conectada à sonda introduzida via retal até perto da região da sutura no coto intestinal distal ou da região da anastomose, conforme o grupo. Infundiu-se a solução duas vezes ao dia, às 7:00 e 19:00horas, em volume variando entre 0,5 e $1 \mathrm{ml}$, até que houvesse extravasamento. Da mesma forma, os animais dos grupos experimento receberam infusões retais com a mesma metodologia, porém de solução isosmolar de butirato de sódio.

Os animais foram mortos nas datas programadas, com dose letal de éter inalatório. Fez-se nova laparotomia e retirou-se a porção desfuncionalizada do intestino nos animais submetidos à cirurgia de Hartmann e à anastomose colônica dos demais.

Em seguida as peças foram fixadas em formalina a $10 \%$ para posterior análise histológica. Realizaram-se cortes com quatro micrômetros de espessura, corados pela técnica do sirius red para avaliação da presença de colágeno, sua maturidade e o grau de ordenação de suas fibras, utilizando-se microscopia óptica com fonte de luz polarizada. As fibras colágenas mais espessas e fortemente birrefringentes apresentam coloração vermelhoalaranjada (colágeno I) e as fibras mais finas e dispersas, fracamente birrefringentes, apresentam coloração esverdeada (colágeno III) ${ }^{10}$. As imagens foram captadas por uma câmera Sonyâ CCD 101, transmitidas a um monitor colorido Trinitron Sonyâ, congeladas e digitalizadas através de placa oculus TCXâ. Finalmente, realizou-se a análise das imagens através do aplicativo Optimasâ 6.0 para "Windows" em microcomputador da linha Pentiumâ. A calibração do sistema baseou-se na densidade óptica dos pontos de resolução (pixels) que formam as imagens, selecionando-se o valor limite de melhor resolução (threshold). Em cada corte histológico, selecionaram- se quatro campos com ampliação de 400x localizados sobre a linha das cicatrizes. Nos 4 campos analisados em cada corte do cólon foi calculado o percentual de área ocupado pelas fibras avermelhadas (colágeno I) e esverdeadas (colágeno III). O valor de colágeno total correspondeu à soma dos valores das áreas vermelhas e verdes.

Os resultados foram analisados estatisticamente, utilizando-se o teste $\mathrm{t}$ de student. Estabeleceu-se $\mathrm{p}=0,05$ ou $5 \%$ como nível para rejeição da hipótese de nulidade.

\section{RESULTADOS}

Não ocorreu óbito de nenhum animal antes do dia estipulado para a morte. No inventário da cavidade abdominal, todos apresentavam aderências do omento à linha de sutura.

$\mathrm{Na}$ análise da densitometria do colágeno nos grupos submetidos à operação de Hartmann, isto é, aqueles que tiveram o segmento distal do cólon excluído do trânsito; os animais que receberam infusões retais de AGCC, examinados no $7^{\circ}$ dia do pós-operatório, monstraram maior área ocupada por colágeno tipo I, com média de 16,2\%. A diferença foi significante $(\mathrm{p}=0,0004)$, quando comparada àquela do grupo controle, que recebeu solução fisiológica (média de 6,8\%). Da mesma forma, o colágeno total obtido pela soma dos colágenos tipo I e III, foi, em média, de 27,2\% das áreas analisadas no grupo HÁ, sendo que no grupo controle este valor foi de $19,3 \%$ ( $\mathrm{p}=0,0028$ ). No $14^{\circ}$ dia do pós-operatório a quantidade de colágeno I e total foi maior nos animais que receberam AGCC; mas o colágeno tipo III esteve presente em quantidade significantemente menor. Esses dados estão ilustrados na Figura 1 e os valores obtidos nos testes estatísticos são monstrados nas Tabelas 1 e 2.

Avaliando os grupos submetidos à anastomose colônica, com interferência do trânsito intestinal, houve aumento da maturação do colágeno

Tabela 1 - Avaliação do uso de AGCC (HA) em comparação com solução salina (HF) no $7^{\circ}$ e $14^{\circ}$ dia do pós-operatório. Valores obtidos no teste t de student referentes aos dados do gráfico da Figura 1.

\begin{tabular}{lccc}
\hline HF x HA & Colágeno I & Colágeno III & Colágeno total \\
\hline 7ํo pós-operatório & $\mathbf{0 , 0 0 0 4}$ & 0,209 & $\mathbf{0 , 0 0 2 8}$ \\
14ํㅜ pós-operatório & $<\mathbf{0 , 0 0 0 1}$ & $\mathbf{0 , 0 0 0 2}$ & $<\mathbf{0 , 0 0 0 1}$ \\
\hline
\end{tabular}


Tabela 2 - Avaliação da evolução do processo cicatricial do $7^{\circ}$ PO para o $14^{\circ}$ PO nos animais submetidos à operação de Hartmann com solução salina (HF) e AGCC (HA). Valores obtidos no teste $t$ de student referentes aos dados do gráfico da Figura 1.

\begin{tabular}{lccc}
\hline $\mathbf{7}^{\mathbf{0}} \times \mathbf{1 4}^{\mathbf{0}}$ pós-operatório & Colágeno I & Colágeno III & Colágeno total \\
\hline HF & 0,142 & $\mathbf{0 , 0 0 0 7}$ & $\mathbf{0 , 0 0 5 2}$ \\
HA & $\mathbf{0 , 0 0 1 2}$ & 0,107 & $\mathbf{0 , 0 0 0 5}$ \\
\hline
\end{tabular}

no grupo que recebeu AGCC tanto no $7^{\circ}$ como no $14^{\circ}$ dia (Figura 2). Já os cólons dos animais do grupo que recebeu solução salina apresentaram maior quantidade de colágeno III quando comparados aos grupo que recebeu o AGCC ( $\mathrm{p}=0,01)$ (tabela 3$)$. Não houve diferença significante na quantidade de colágeno total entre os dois grupos. Na avaliação da evolução do processo cicatricial, houve aumento da maturação do colágeno tanto no grupo controle como no grupo experimento (tabela 4).

\section{DISCUSSÃO}

Ao suturar-se a porção distal do intestino grosso e confeccionar-se uma colostomia terminal, privamos o reto de sua fonte natural de AGCC e conseqüentemente teremos um coto retal atrófico e com um processo cicatricial distinto pela possível alteração no metabolismo do colágeno ${ }^{11,12}$. Desta forma, em situações de ausência de trânsito intestinal, tem sido orientada a suplementação de AGCC tanto por aplicação local direta, via retal, quanto por via endovenosa ${ }^{13}$, na tentativa de minimizar os efeitos atróficos normalmente observados.

Em ratos, verificou-se que após quatro semanas, a alça intestinal desfuncionalizada e excluída do trânsito fecal é capaz de tornar-se atrófica, inclusive diminuindo seu conteúdo de colágeno, o que resulta numa menor resistência mecânica do tecido ${ }^{1,2}$. Por outro lado, a instilação de AGCC nesses tecidos, apesar de preservar a superfície da mucosa, não demonstrou ser capaz de alterar o conteúdo de colágeno, tampouco melhorar sua resistência mecânica ${ }^{14}$. Em outras palavras, os AGCC não se mostraram eficazes no aumento da resistência mecânica da parede atrófica do cólon.

Rolandelli et $a l^{8}$ demonstraram que a infusão intralunimar de AGCC facilita o processo cicatricial de tecidos lesados, melhorando a resistência de anastomoses colônicas em ratos. Mecanismos possíveis que possam mediar esse efeito incluem o seguin-

Tabela 3 - Comparação entre os grupos do AGCC (AA) e daa solução salina (AF) no $7^{\circ}$ e $14^{\circ}$ dia após a anastomose colônica. Valores do teste t de student referentes aos dados da Figura 2.

\begin{tabular}{lccc}
\hline AF $\mathbf{x}$ AA & Colágeno I & Colágeno III & Colágeno Total \\
\hline 7 dias após cirurgia & $\mathbf{0 , 0 0 6}$ & $\mathbf{0 , 0 1}$ & 0,053 \\
14 dias após cirurgia & $\mathbf{0 , 0 3 5}$ & 0,741 & 0,648 \\
\hline
\end{tabular}

Tabela 4 - Avaliação da evolução do processo cicatricial do $7^{\circ}$ para o $14^{\circ}$ dia do pós operatório no grupo tratado com solução salina (AF) e no grupo tratado com AGCC (AA) nos animais submetidos à anastomose colônica. Valores obtidos no teste t de student referentes aos dados do gráfico da Figura 2.

\begin{tabular}{lccc}
\hline $\mathbf{7}^{\mathbf{0}} \mathbf{1 4 ^ { \mathbf { 0 } }}$ PO & Colágeno I & Colágeno III & Colágeno Total \\
\hline AF & $\mathbf{0 , 0 0 2}$ & 0,069 & $\mathbf{0 , 0 2 1}$ \\
AA & $\mathbf{0 , 0 0 1}$ & 0,75 & 0,322 \\
\hline
\end{tabular}




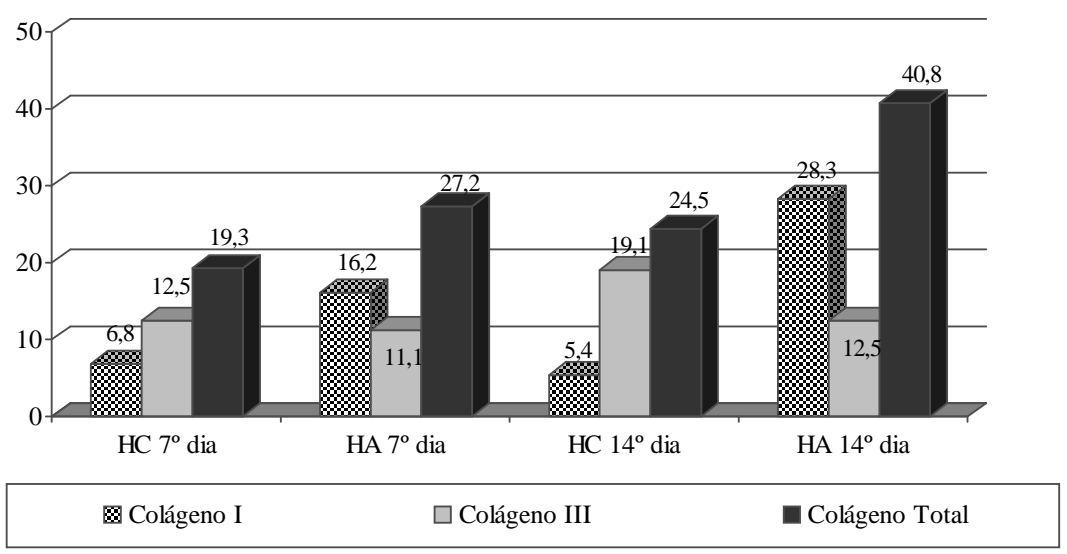

Figura 1 - Valores médios de colágeno I, III e total obtidos dos animais submetidos à operação de Hartmann. Valores em porcentagem da área analisada.

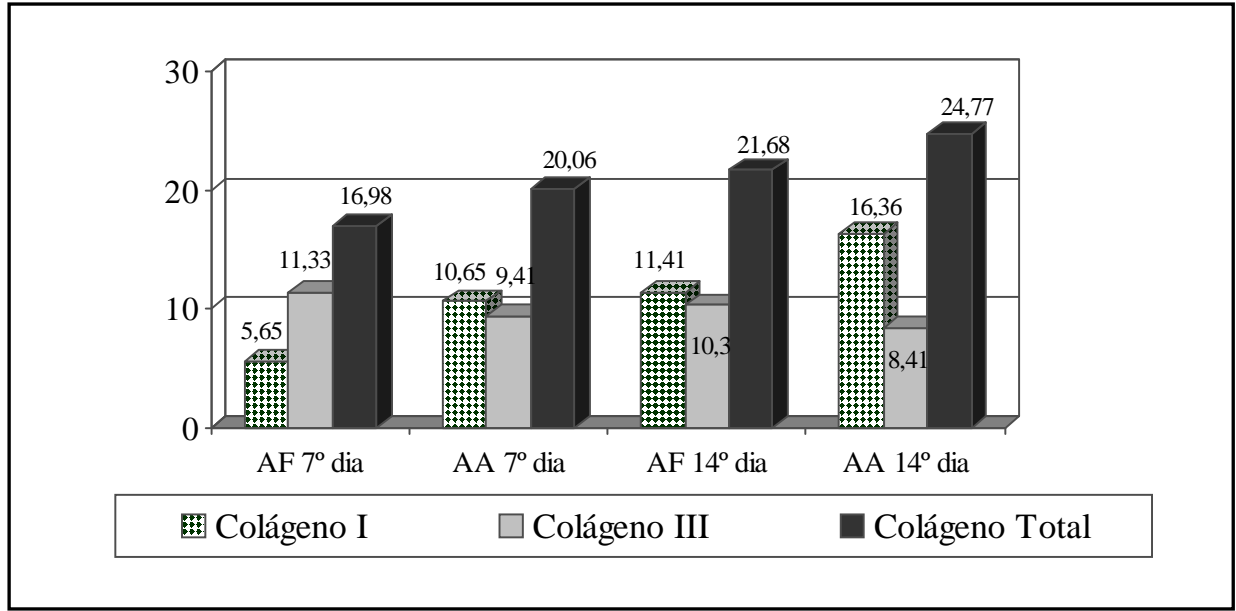

Figura 2 - Valores médios do colágeno I, III e total dos grupos submetidos à anastomose colônica. Valores correspondentes a \% da área analisada.

te: aumento da proliferação celular da mucosa colônia, acelerando a reepitelização e aumento do fluxo sangüíneo, com conseqüente incremento da oferta de oxigênio e aceleração da maturação do colágeno ${ }^{15}$.

Friedel e Levine ${ }^{16}$ mantiveram ratos em nutrição parenteral total, recebendo infusões de AGCC no cólon proximal e observaram aumento de massa e de DNA da mucosa, sem contudo verificar alterações na função absortiva da víscera .

Kissmeyer-Nielsen et al ${ }^{14}$ demonstraram,em ratos, que enemas de AGCC promovem um aumento do trofismo do cólon, preservando seu epitélio de revestimento. A instilação de AGCC por sete e 14 dias não alterou, entretanto, o conteúdo de hidroxiprolina e conseqüentemente de colágeno no tecido excluído do trânsito fecal.

Em 1997, Rolandelli et al $^{13}$ avaliaram a ação do AGCC aplicado via endovenosa, e também não encontraram diferença no conteúdo de hidroxiprolina; mas observaram que a resistência mecânica era maior no grupo que havia recebido AGCC em comparação com o grupo controle.

A técnica de avaliação do colágeno utilizada no presente estudo foi diferente daquela descrita na literatura, buscando-se identificar não apenas a quantidade de colágeno, mas principalmente seu grau de 
maturação. Uma vez que a maturação do colágeno depende da oxigenação dos tecidos, a qual depende da neovascularização induzida por fatores produzidos pelo epitélio, seria de se esperar que o aumento do grau de epitelização induzido pelo AGCC tivesse como efeito final maior maturação das fibras colágenas. Neste estudo, observamos tanto no $7^{\circ}$ quanto no $14^{\circ}$ dia do pós-operatório, maior porcentagem de área ocupada por fibras colágenas do tipo I no grupo que recebeu AGCC, além de maior porcentagem de colágeno total

$\mathrm{Na}$ avaliação da evolução do processo cicatricial, comparando-se os resultados do 7으 e 14은 dia do pós-operatório, observamos que tanto nos animais que receberam AGCC quanto naqueles que receberam apenas solução salina, houve aumento do colágeno total na linha de sutura. Interessante notar que, nos animais do grupo controle, esse aumento do colágeno total ocorreu à custa do colágeno III ( $\mathrm{p}=0,0007)$; não houve aumento significante do colágeno I neste grupo. Por outro lado, os animais que receberam o AGCC apresentaram aumento do colágeno total à custa do colágeno $\mathrm{I}(\mathrm{p}=0,0005)$, não havendo diferença na quantidade de colágeno III.

Conclui-se que nos ratos em que foi realizada infusão intraluminal de AGCC em cólon desfuncionalizado, há maior concentração de colágeno
I e total na linha de sutura quando comparados com o grupo controle. $\mathrm{O}$ aumento do colágeno total do $7^{\circ}$ para o $14^{\circ}$ dia de pós-operatório já era esperado; mas a grande diferença esteve relacionada ao tipo de colágeno encontrado. Nos animais que receberam solução salina, houve apenas produção de colágeno neste período, traduzido pelo aumento do colágeno III, sem aumento do colágeno I. Nos animais que receberam AGCC o colágeno III existente sofreu maturação, levando ao aumento do colágeno I; mas novo colágeno foi também produzido, pois a quantidade de colágeno III se manteve semelhante mesmo com a maturação do colágeno imaturo préexistente.

Interessante ainda é a observação que nos animais submetidos à anastomose colônica, isto é, naqueles onde o trânsito fecal não foi interrompido, a percentagem de colágeno total e de colágeno maduro foi semelhante nos ratos que receberam infusão de solução salina isotônica em relação aos que receberam infusão de solução de AGCC. A percentagem de área da anastomose ocupada pelo colágeno imaturo,contudo, foi significantemente maior nos animais que receberam infusão de solução salina isotônica. Isso leva a crer que os ácidos graxos de cadeia curta desempenham papel fundamental na maturação do colágeno.

\begin{abstract}
Background: The aim of the present study was to evaluate the intraluminal effects of short chain fatty acids (SCFA) on the healing of defunctioned colon and in the presence of faecal loading in rats. Methods: Fifty adult Wistar rats were divided in four groups. Two of them, twenty six rats, were submitted to Hartmann's procedure (HC - Hartmann Control - and HSCFA - Hartmann SCFA) and colonic anastomosis were performed in the other two groups (AC - Anastomosis Control - and ASCFA - Anastomosis SCFA). The control groups $(H C$ and $A C)$ received rectal infusions of saline, while the experimental groups (HSCFA and ASCFA) received the same kind of infusion but with an isosmolar solution of sodium butyrate at 80mmol/l (SCFA). The animals were sacrificed at the $7^{\text {th }}$ and $14^{\text {th }}$ postoperative day. Histologic preparations with sirius red staining were performed to analyse the collagen densitometry by optic microscopy with a polarized light. Collagen I, collagen III and total collagen were quantified by a computer software. Results: In the groups submitted to Hartman's operation - with bowel rest - the animals submitted to rectal infusions of SCFA showed an increase in the quantity of total and collagen I. Evaluating the groups submitted to colonic anastomosis - with interference of intraluminal bulk - there was an increase in collagen I in the experimental group. The interference of the diet bowel content in the healing process, with or without SCFA rectal infusions, was analyzed crossing the groups of different surgical procedures. Conclusion: The main effect of rectal infusions of SCFA was related to the collagen I, either with or without interference of the intestinal bulk. The presence of diet bowel content also increased the collagen production.
\end{abstract}

Key Words: Fatty acids, volatile; Wound healing; Colon; Collagen; Anastomosis, surgical. 


\section{REFERÊNCIAS}

1. Kissmeyer-Nielsen P, Christensen H, Laurberg S Decrease in collagenous proteins and mechanical strength of distal colon after diverting colostomy in rats. Int J Colorectal Dis, 1993, 8(3):120124.

2. Kissmeyer-Nielsen P, Christensen H, Laurberg S Diverting colostomy induces mucosal and muscular atrophy in the rat distal colon. Gut, 1994, 35(9):12751281.

3. Mosdell DM, Doberneck RC - Morbidity and mortality of ostomy closure. Am J Surg, 1991, 162(6):633-636.

4. Keck JO, Collopy BT, Ryan PJ, et al. - Reversal of Hartmann's procedure: effect of timing and technique on ease and safety. Dis Colon Rectum, 1994, 37(3):243248.

5. Pearce NW, Scott S, Karran SJ - Timing and method of reversal of Hartmannn's procedure. Br J Surg, 1992, 79(8):839-841.

6. Roediger WE - Utilization of nutrients by isolated epithelial cells of the rat colon. Gastroenterology, 1981, 83(3):424-429.

7. Sakata T, von Engelhardt W - Stimulatory effect of short chain fatty acids on the epithelial cell proliferation in rat large intestine. Comp Biochem Physiol A, 1983, 74(2):459-462.

8. Rolandelli RH, Koruda MJ, Settle RG, et al. - Effects of intraluminal infusion of short-chain fatty acids on the healing of colonic anastomosis in the rat. Surgery, 1986, 100(2):198-204.

9. Mortensen FV, Langkilde NC, Joergensen JC, et al. Short-chain fatty acids stimulate mucosal cell proliferation in the closed human rectum after Hartmann's procedure. Int J Colorectal Dis, 1999, 14(3):150-154.
10. Junqueira LC, Cossermelli W, Brentani R - Differential staining of collagens type I, II and III by Sirius Red and polarization microscopy. Arch Histol Jpn, 1978, 41(3):267-274.

11. Blomquist P, Jiborn $\mathrm{H}$, Zederfeldt $\mathrm{B}$ - The effect of relative bowel rest and healing of colonic anastomoses. Breaking strength and collagen in the colonic wall following left colon resection and anastomosis in the rat. Acta Chir Scand, 1984, 150(8):671-675.

12. Blomquist $\mathrm{P}$, Ahonen J, Jiborn $\mathrm{H}$, et al. - The effect of relative bowel rest and healing of colonic anastomoses. Collagen synthesis and content in the colonic wall after left colon resection and anastomosis in the rat. Acta Chir Scand, 1984, 150(8):677-681.

13. Rolandelli RH, Buckmire MA, Bernstein KA Intravenous butyrate and healing of colonic anastomoses in the rat. Dis Colon Rectum, 1997, 40(1):67-70.

14. Kissmeyer-Nielsen P, Mortensen FV, Laurberg S, et al. - Transmural trophic effect of short chain fatty acid infusions on atrophic, defunctioned rat colon. Dis Colon Rectum, 1995, 38(9):946-951.

15. Mortensen FV, Hessov I, Birke H, et al. Microcirculatory and trophic effects of short chain fatty acids in the human rectum after Hartmann's procedure. Br J Surg, 1991, 78(10):1208-1211.

16. Friedel D, Levine GM - Effect of short-chain fatty acids on colonic function and structure. JPEN J Parenter Enteral Nutr, 1992,16(1):1-4.

Endereço para correspondência:

Maria de Lourdes Pessole Biondo-Simões Rua Ari José Valle, 1987, Santa Felicidade CEP 82030-000, Curitiba-Paraná

Telefone 0XX 41.297.43.59 ou 0XX 41.322.48.84

E-mail: Biondo@avalon.sul.com.br 